\title{
Stress-Level Cortisol Treatment Impairs Inhibitory Control of Behavior in Monkeys
}

\author{
David M. Lyons, Jacqueline M. Lopez, Chou Yang, and Alan F. Schatzberg \\ Department of Psychiatry and Behavioral Science, Stanford University School of Medicine, Stanford, \\ California 94305-5485
}

\begin{abstract}
Most studies of cortisol-induced cognitive impairments have focused on hippocampal-dependent memory. This study investigates a different aspect of cognition in a randomized placebocontrolled experiment with monkeys that were treated with cortisol according to a protocol that simulates a prolonged stress response. Young adult and older adult monkeys were assigned randomly to placebo or chronic treatment with cortisol in a $2 \times 2$ factorial design ( $n=8$ monkeys per condition). Inhibitory control of behavior was assessed with a test shown previously in primates to reflect prefrontal cortical dysfunction. Failure to inhibit a specific goal-directed response was evident more often in older adults. Treatment with cortisol increased this propensity in both older and young adult monkeys. Age-related differences in re-
\end{abstract}

sponse inhibition were consistent across blocks of repeated test trials, but the treatment effects were clearly expressed only after prolonged exposure to cortisol. Aspects of performance that did not require inhibition were not altered by age or treatment with cortisol, which concurs with effects on response inhibition rather than nonspecific changes in behavior. These findings lend support to related reports that cortisol-induced disruptions in prefrontal dopamine neurotransmission may contribute to deficits in response inhibition and play a role in cognitive impairments associated with endogenous hypercortisolism in humans.

Key words: glucocorticoids; dopamine; prefrontal cortex; stress; aging; manual laterality; cognition; response inhibition
Research on cortisol-induced cognitive impairments has focused primarily on the hippocampus where cortisol binds with different affinities to mineralocorticoid and glucocorticoid receptors (McEwen and Sapolsky, 1995; de Kloet et al., 1999; Newcomer et al., 1999). Here we address a different aspect of cognition using a test shown previously in primates to reflect prefrontal cortical dysfunction (Diamond, 1990; Taylor et al., 1990c; Dias et al., 1996; Jentsch et al., 1999). A clear Plexiglas box with one open side is baited with a favorite food treat. When the box opening is oriented straight toward the test subject, food retrieval is achieved by line-of-sight reaching into the center of the box. When the box is rotated $90^{\circ}$ so the opening is oriented toward either side, inhibition of line-ofsight reaching is required to retrieve food from the clear baited box. Reaches aimed straight toward the center of the box when the opening is oriented toward either side are scored as line-of-sight response inhibition errors, which seldom occur when tests are conducted with a baited opaque Plexiglas box (Diamond, 1990; Taylor et al., 1990c).

Inhibitory control of the line-of-sight response improves gradually with frontal lobe maturation in primates tested with a baited clear box (Diamond, 1990). In addition to line-of-sight response inhibition errors, awkward retrievals with the hand contralateral to the box opening are common in human infants and infant monkeys (Diamond, 1990). Deficits expressed early in development are reproduced in marmosets and rhesus monkeys by structural lesions in the adult prefrontal cortex (Diamond et al., 1989; Diamond, 1990; Dias et al., 1996). Identical line-of-sight response inhibition deficits are produced in adult vervet monkeys by treatment with 1-methyl-4-phenyl-1,2,3,6-tetrahydropyridine (MPTP) (Taylor et al., 1990a,b,c), a neurotoxin that depletes dopamine in the substantia nigra and frontostriatal circuitry (Di Paolo et al., 1986; Elsworth et al., 1987; Slovin et al., 1999). Impaired inhibition of line-of-sight reaching is also produced in adult vervet monkeys treated repeat-

Received April 20, 2000; revised July 14, 2000; accepted Aug. 3, 2000

This research was supported by the Nancy Pritzker Network and Public Health Service (Washington, D.C.) Grant MH 47573. We gratefully acknowledge Erica Didier, Tom Jordan, and Sonia Lupien for their advice and technical assistance.

Correspondence should be addressed to Dr. David M. Lyons at the above address. E-mail: dmlyons@stanford.edu.

Copyright (C) 2000 Society for Neuroscience $0270-6474 / 00 / 207816-06 \$ 15.00 / 0$ edly with phencyclidine, which selectively decreases dopamine use in the prefrontal cortex (Jentsch et al., 1997, 1999). Inhibitory control of behavior is restored by clozapine-induced increases in prefrontal dopamine use in monkeys treated previously with phencyclidine (Jentsch et al., 1997). That diminished dopamine use mirrors the effect of direct structural damage to the prefrontal cortex is consistent with studies of spatial delayed working memory but not other prefrontal-dependent tasks (Brozoski et al., 1979; Roberts et al., 1994; Collins et al., 1998).

Cortisol-induced changes in response inhibition are examined in this study of young and older adult squirrel monkeys tested on the line-of-sight reaching response task with a baited clear Plexiglas box. All monkeys were trained for 10 consecutive days with the box opening oriented straight to reinforce the line-of-sight reaching response. The orientation of the box was then varied systematically with straight-facing trials interspersed among trials conducted with the box opening oriented toward either side.

\section{MATERIALS AND METHODS}

A total of 32 female squirrel monkeys (Saimiri sciureus) of Guyanese origin that were born and raised at the Stanford University Primate Facility served as subjects. Sixteen monkeys were young adults with a median age of 3 years (range, 27-44 months). The other 16 monkeys were older adults with a median age of 12 years (range, 116-171 months). Squirrel monkeys achieve sexual maturity at $2.5-3.5$ years, and their life span is $\sim 21$ years (Brady, 2000).

Monkeys were housed and tested individually in wire-mesh cages $(60 \times$ $60 \times 90 \mathrm{~cm}$ ) that allowed visual, auditory, olfactory, and limited tactile contact between adjacent animals. Cages were located in a climatecontrolled room on a 12:12 hr light/dark cycle. All procedures were conducted in accordance with and as required by the Animal Welfare Act and approved by Stanford University's Administrative Panel on Laboratory Animal Care.

Training and test procedures. The apparatus used for training and testing was a clear Plexiglas box $(8 \times 8 \times 8 \mathrm{~cm})$ with one open side baited with a marshmallow treat. The box was locked into place on a $12 \times 50 \mathrm{~cm}$ horizontal tray secured to a tripod placed in front of each monkey's cage. Initially, all monkeys were administered 10 training trials per day for 10 consecutive days with the box opening always oriented straight. Thereafter, monkeys were administered 10 test trials per day for 21 consecutive days with the orientation of the box opening varied systematically (Fig. 1). On each day of testing, the box opening was oriented straight on the 1st, 4th, 7 th, and 10th trials. For the 2nd, 5th, and 8th daily trials, the box was rotated $90^{\circ}$ so the opening was oriented toward the left. For the 3rd, 6th, 
Training Phase

10 trials/monkey/day
with the
box-opening always
oriented straight

Test Phase

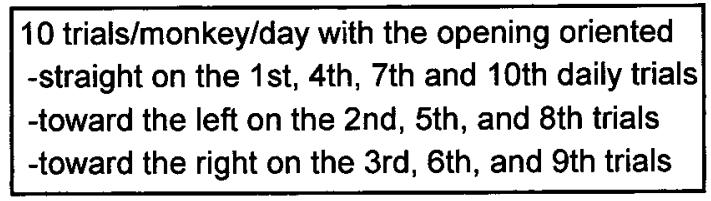

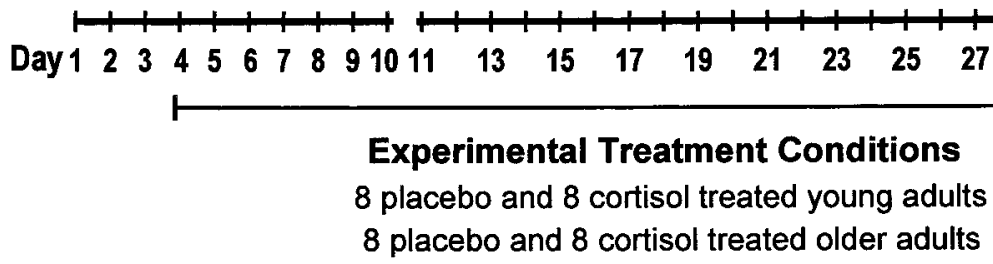

Figure 1. Schematic representation of the experimental design.

and 9th daily trials, the box was rotated $90^{\circ}$ so the opening was oriented toward the right.

Each trial lasted $30 \mathrm{sec}$ or was terminated as soon as the marshmallow was retrieved. During the ensuing $30 \mathrm{sec}$ intertrial interval, the experimenter removed the box from the tray, rebaited the box for the subsequent trial, and recorded the direction of each reach attempt and the hand used on successful retrievals. After completion of the daily test trials, monkeys were fed unrestricted amounts of commercial monkey chow with fresh fruit supplements. The following morning $4 \mathrm{hr}$ before testing, all uneaten food was removed. Each monkey was tested at the same time of day between 14:00 and 17:00 hr.

Treatment conditions. Eight young and 8 older adult monkeys were assigned randomly to each of two treatment conditions in a $2 \times 2$ factorial design. In one condition, cortisol hemisuccinate (Steraloids, Newport, RI) was dissolved in water $(420 \mathrm{mg} / 1)$ flavored with red cherry juice and provided to the monkeys as their sole source of water in standard drinking bottles. In the placebo condition, monkeys were provisioned in an identica manner with red-dyed drinking water. Placebo and cortisol treatment conditions were initiated $7 \mathrm{~d}$ before the $21 \mathrm{~d}$ test phase of the study and were maintained continuously for the duration of the experiment. In a pilot study we determined that amounts of cortisol consumed by the use of this protocol result in plasma levels of cortisol and adrenocorticotropic hormone (ACTH) that approximate a previously described chronic stress response (Lyons et al., 1995, 1999). Because drinking water is consumed during active daylight hours, this mode of administration preserves normal circadian rhythms and eliminates the need for repeated injections that can disrupt performance on tests of behavior.

Cortisol consumption was monitored in blood samples $(0.8 \mathrm{ml})$ obtained from manually restrained monkeys by femoral venipuncture for determinations of cortisol and ACTH using previously described procedures (Lyons et al., 1995, 1999). Each monkey was sampled $10 \mathrm{~min}$ after completion of the 10 daily trials $6,8,10,18$, and $28 \mathrm{~d}$ after initiation of the cortisol treatment protocol. Most samples (70\%) were collected within 2 min of cage entry (median latency to sample collection $=105 \mathrm{sec}$; range 33-406 sec), and all but six samples $(<4 \%)$ were collected within $4 \mathrm{~min}$. Plasma levels of squirrel monkey cortisol and ACTH measured within these time limits by the use of these procedures do not reflect stressful sampling effects (Lyons et al., 1995, 1999).

Data analysis. Behavioral data were analyzed with repeated-measures ANOVA. The box-opening orientation was considered a within-subjects factor, whereas age and treatment were considered between-subjects factors. Similar ANOVAs were used to analyze plasma levels of cortisol and ACTH.

For straight-facing test trials, a standard index of manual laterality was derived by subtracting the number of left-hand retrievals from the number of right-hand retrievals and dividing the difference by the total number of retrievals (Westergaard et al., 1998). This index quantifies manual laterality along a continuum from strongly left-handed (negative scores) to strongly right-handed (positive scores), with zero indicating the absence of a lateral bias. Each monkey's manual laterality score was considered statistically significant $(p<0.01)$ when the binomial $z$-score-transformed value exceeded 2.54, as described elsewhere in greater detail (Milliken et al., 1991).

To estimate the independent contributions of age, cortisol treatment, and manual laterality effects on the propensity to inhibit line-of-sigh reaching, an ordered series of linear least squares regression equations was analyzed by the use of the hierarchical approach (Cohen and Cohen, 1983). This regression analysis and the ANOVAs described above were performed with the MGLH module in Systat (Evanston, IL). All test statistics were evaluated with two-tailed probabilities, and descriptive statistics are presented as the mean \pm SEM.

\section{RESULTS}

All monkeys retrieved the marshmallow treat with their first reach attempt on each of the training trials administered with the box opening oriented straight. When subsequent straight-facing test trials were interspersed among trials administered with the box opening oriented toward either side, the marshmallow treat was also retrieved but often after reaches that failed to result in the immediate recovery of the food. On average, each monkey made $26 \pm 6$ reach attempt errors (mean \pm SEM) on test trials administered with the box opening oriented straight. Twice as many errors $(56 \pm 4)$ were made by each monkey when the opening was oriented toward the left or right $\left[F_{(1,31)}=5.21 ; p<0.03\right.$ for error rates standardized on a per trial basis].

\section{Errors with the box opening oriented straight}

Most test trials administered with the box opening oriented straight $(75 \%)$ were preceded immediately by a trial conducted with the opening oriented toward the right (Fig. 1). Despite this regularity, monkeys did not exhibit a tendency to repeat the previously correct response; $47 \pm 5 \%$ of all errors were toward the left, and $42 \pm 5 \%$ of all errors were toward the right. A small percentage of errors were reach attempts directed toward the top of the box $(2 \pm 1 \%)$ or were handling errors performed inside the box that failed to result in the recovery of food $(9 \pm 2 \%)$. Age- and cortisol treatment-related differences were not statistically significant for any of these errors committed on test trials with the box opening oriented straight.

\section{Errors with the box opening oriented left or right}

Each test trial administered with the box opening oriented left was preceded immediately by a trial conducted with the opening oriented straight (Fig. 1). In a similar manner, each trial administered with the box opening oriented right was preceded immediately by a trial conducted with the opening oriented toward the left. Despite these regularities in the orientation of the opening, most errors consisted of line-of-sight reaches directed straight toward the box. When the box opening was oriented left, $36 \pm 3 \%$ of all errors were directed toward the right, whereas $55 \pm 3 \%$ of all errors were line-of-sight reaches directed straight toward the box $\left[F_{(1,28)}=\right.$ 16.7; $p<0.001$ ]. Identical outcomes were evident when the box opening was oriented right; $37 \pm 3 \%$ of all errors were directed toward the left, whereas $55 \pm 3 \%$ of all errors were line-of-sight reaches directed straight toward the box $\left[F_{(1,28)}=17.3 ; p<0.001\right]$.

Both age and the cortisol treatment influenced performance on trials conducted with the opening oriented toward either side. Line-of-sight response inhibition errors directed straight toward the box were performed most often by the older adults. Treatment with cortisol increased response inhibition errors in both the older and young adult monkeys (Fig. 2). Significant main effects for age $\left[F_{(1,28)}=8.18 ; p<0.01\right]$ and treatment $\left[F_{(1,28)}=5.48 ; p<0.05\right]$ were discerned in the age (young vs older) $\times$ treatment (cortisol vs placebo) $\times$ box opening (left vs right) ANOVA. The box orientation main effect and all four interaction terms in this analysis were not statistically significant.

Response inhibition errors directed straight toward the box when the opening was oriented toward either side were grouped into $7 \mathrm{~d}$ 
a

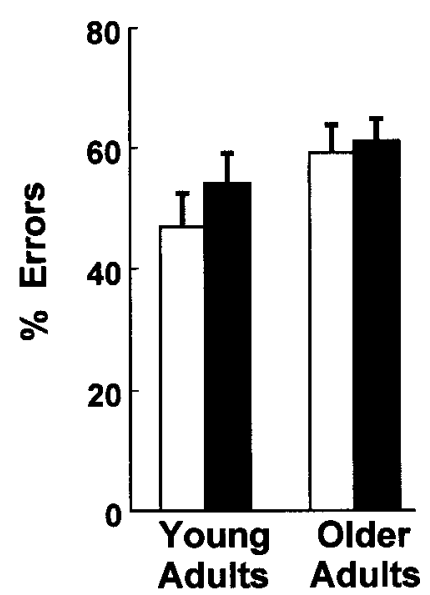

b

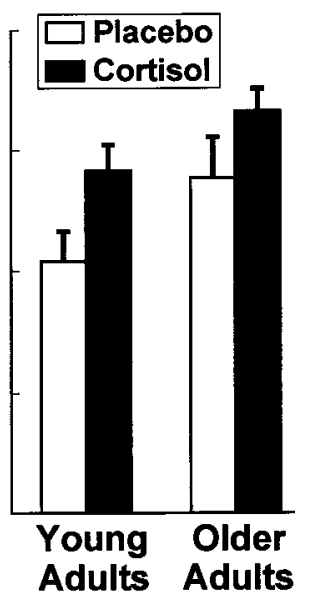

Figure 2. Response inhibition errors directed straight toward the box when the box opening was oriented toward the left $(a)$ or right $(b)$ were evident more often in older adults. Chronic treatment with cortisol increased this propensity in older and young adult monkeys $(n=8$ monkeys per condition).

blocks of repeated trials and analyzed for changes over time (Fig. 3 ). Error rates declined with repeated test trials as revealed by ANOVA [repeated-blocks main effect $\left.F_{(2,56)}=35.63 ; p<0.001\right]$. Age-related differences in response inhibition errors were consistent across blocks of repeated test trials [age main effect $F_{(1,28)}=$ 7.47; $p<0.02$ ], whereas treatment effects were clearly expressed only on the last block of trials $\left[F_{(1,28)}=5.02 ; p<0.05\right]$.

\section{Individual differences in manual laterality}

Reach attempt errors performed within a given trial preceded the retrieval of food. Nearly all retrievals were performed with the hand ipsilateral to the box opening on left- and right-oriented test trials. The so-called awkward retrieval was performed with the contralateral hand $<4 \%$ of the time. Age- and cortisol treatmentrelated differences were not significant for awkward retrievals performed using the contralateral hand.

Individual differences in manual laterality were discerned on trials conducted with the box opening oriented straight. During the series of 100 training trials, 16 monkeys demonstrated a significant left-hand bias $(p<0.01), 13$ monkeys demonstrated a significant

right-hand bias $(p<0.01)$, and 3 monkeys were scored as ambidextrous. Individual differences in manual laterality during training predicted subsequent differences in manual laterality scored on the 84 straight-facing test trials (intraclass correlation $=0.91 ; p<0.001$ ).

\section{Manual laterality and response inhibition}

Reliable differences in manual laterality predicted differences in the propensity to inhibit, when required, the line-of-sight reaching response. Significantly fewer line-of-sight response inhibition errors were performed by monkeys with a left-hand bias, regardless of whether the box opening was oriented toward the left or right (Fig. 4). A significant manual laterality main effect $\left[F_{(2,29)}=4.04 ; p<\right.$ 0.03 ] was discerned by ANOVA, but the box-opening orientation main effect and manual laterality $\times$ box-opening interaction failed to achieve statistical significance.

The relationship between response inhibition and laterality was not caused by spurious age or treatment effects as indicated by hierarchical regression analysis. With age entered first in the linear least squares equation, the difference between young and older adults explained $17 \%$ of the variance in response inhibition errors made with the box opening oriented toward either side $\left[F_{(1,30)}=\right.$ 6.16; $p<0.02]$. With age and cortisol treatment entered together in the subsequent regression equation, an additional $11 \%$ of the variance in response inhibition errors was explained by placebocontrolled treatment with cortisol $\left[F_{(1,29)}=4.62 ; p<0.05\right]$ beyond that attributed to the age effect alone. With age, treatment, and manual laterality all entered in the final equation, an additional $10 \%$ of the variance in response inhibition errors was explained by manual laterality $\left[F_{(1,28)}=4.28 ; p<0.05\right]$ beyond that attributed to age and treatment with cortisol.

\section{Neuroendocrine assessments}

Chronic treatment with cortisol in drinking water resulted in stresslike increases in plasma cortisol levels and reductions in plasma levels of ACTH. Mean cortisol levels in the cortisol-treated monkeys were significantly greater than those in the placebo controls $\left[437 \pm 41\right.$ vs $\left.144 \pm 17 \mu \mathrm{g} / \mathrm{dl} ; F_{(1,28)}=49.8 ; p<0.001\right]$. The converse was evident for ACTH $\left[10 \pm 2\right.$ vs $52 \pm 8 \mathrm{pg} / \mathrm{ml} ; F_{(1,28)}=$ 23.2; $p<0.001]$. Age-related main effects and age $\times$ cortisol treatment interactions were not statistically significant.

\section{DISCUSSION}

Stress-level cortisol treatment impaired response inhibition at a level less severe than that reported previously for prefrontal lesions (Diamond et al., 1989; Diamond, 1990; Dias et al., 1996) and diminished prefrontal dopamine use in monkeys treated repeatedly

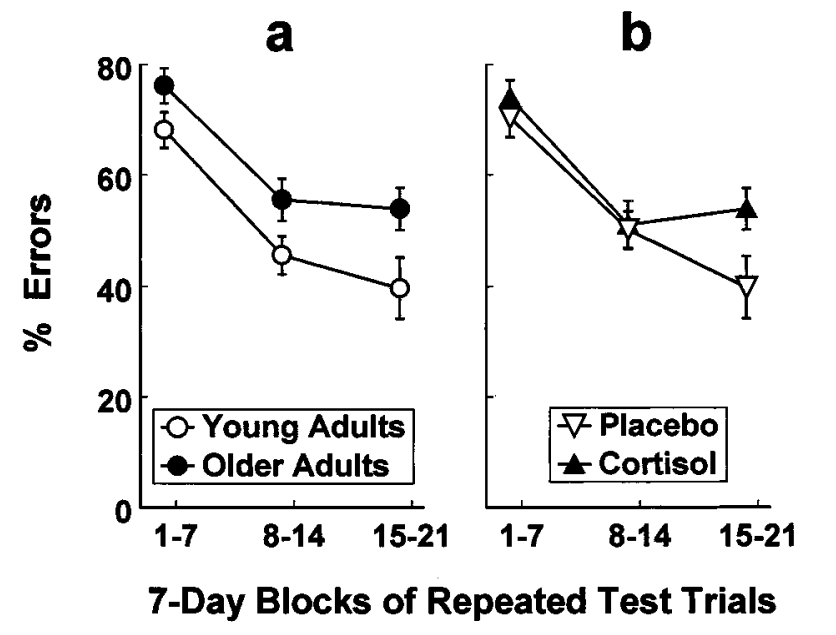

Figure 3. Results from repeated measures ANOVA showed that agerelated differences in response inhibition errors were consistent across $7 \mathrm{~d}$ blocks of repeated trials $(a ; n=16$ monkeys per age group), whereas treatment effects were clearly expressed only after prolonged exposure to cortisol $(b ; n=16$ monkeys per treatment).

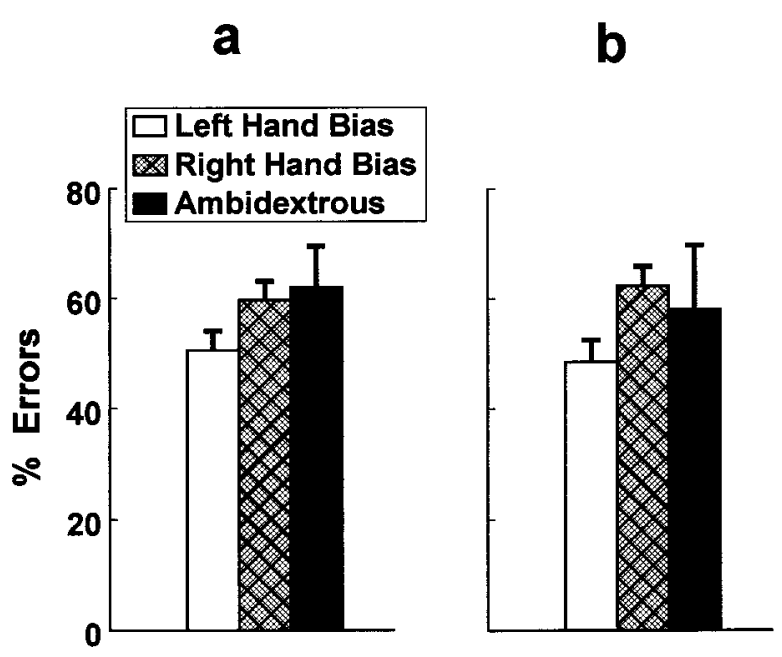

Figure 4. Monkeys with a left-hand bias $(n=16)$ performed significantly fewer response inhibition errors when the box opening was oriented toward the left $(a)$ or right $(b)$ compared with monkeys with a right-hand bias $(n=$ 13 ) or monkeys scored as ambidextrous $(n=3)$. 
with phencyclidine (Jentsch et al., 1997, 1999). Failure to inhibit line-of-sight reaching was evident more often in older squirrel monkey adults. Treatment with cortisol increased this propensity in both older and young adult monkeys. Age-related differences in response inhibition were consistent across blocks of repeated test trials, but the treatment effects were clearly expressed only after prolonged exposure to cortisol. Aspects of performance that did not require inhibition were not altered by age or treatment with cortisol, which concurs with effects on response inhibition rather than nonspecific changes in behavior.

Most studies of cortisol-induced cognitive impairments in humans have focused on hippocampal-dependent memory. Four days of placebo-controlled stress-level cortisol administered to healthy humans impairs hippocampal-dependent memory (Newcomer et al., 1999), as does stress-induced increases in endogenous cortisol levels (Kirschbaum et al., 1996; Lupien et al., 1997) and elevated cortisol at baseline (Lupien et al., 1998). Endogenous hypercortisolism has been associated with hippocampal atrophy and deficits in declarative memory in patients with Cushing's syndrome, dementia of the Alzheimer type, schizophrenia, and major depression (de Leon et al., 1988; O'Brien et al., 1996; Nelson et al., 1998; Newcomer et al., 1998; Sheline et al., 1999; Starkman et al., 1999).

Our findings reflect a different aspect of cognition because surgical ablations that impair hippocampal-dependent memory spare inhibition in monkeys assessed on the line-of-sight reaching response test (Diamond et al., 1989). Chronic treatment with hydrocortisone in healthy young men also produces spatial workingmemory deficits that resemble those seen in surgical patients after frontal lobe excisions, but not temporal lobe excisions or amygdalohippocampectomies (Young et al., 1999). Another study reported in healthy young men that prefrontal-dependent item-recognition working memory is impaired by acute high-dose hydrocortisone infusions administered shortly before and during cognitive testing (Lupien et al., 1999). Continuous treatment with cortisol in squirrel monkeys did not immediately influence response inhibition, but prefrontal-dependent inhibitory deficits in monkeys emerged over repeated test trials.

As demonstrated previously in vervet monkey research (Taylor et al., 1990b), response inhibition errors directed straight toward the box when the opening was oriented toward either side decreased over repeated test trials. Consistent age-related differences in response inhibition errors were evident in squirrel monkeys across blocks of repeated trials, but cortisol treatment effects on response inhibition were confined to the last block of trials. Daily treatments of corticosterone likewise diminish inhibitory control of goal-directed routines in studies conducted with rodents (Hennessy et al., 1973; Micco et al., 1979). But while learning to perform these simple routines, rats treated daily with corticosterone did not differ significantly from placebo controls (Hennessy et al., 1973).

Impaired response inhibition occurs regularly in older animals (Bartus et al., 1979; Means and Holsten, 1992; Milgram et al., 1994) and is linked in older humans to age-related atrophy in prefrontal volumes assessed in vivo by magnetic resonance imaging (Raz et al., 1998; Kim et al., 1999). Research on normal aging has not consistently established a loss of neurons in primate prefrontal cortex (Peters, 1993), but other age-related changes are known to occur. These include a reduction in cerebral white matter volumes (Peters et al., 1996), breakdown in the integrity of myelin around axons (Peters et al., 2000), diminished synaptic densities in prefrontal cortex (Peters et al., 1998), and a decline in prefrontal dopamine levels (Goldman-Rakic and Brown, 1981; Wenk et al., 1989).

Recent evidence suggests that prefrontal cognitive deficits may arise from disruptions in forebrain dopamine neurotransmission induced by excessive exposure to cortisol. Glucocorticoid receptors bind cortisol in dopamine cell bodies (Harfstrand et al., 1986) and primate prefrontal cortex (Sanchez et al., 2000). Cortisol-induced disruptions in dopamine neurochemistry have not yet been examined in primates, but treatment with corticosterone or its removal by adrenalectomy alters forebrain dopamine physiology in rodents. Both increased and diminished dopamine levels have been found after treatment with corticosterone in rats (Thomas et al., 1994; Piazza et al., 1996; Lindley et al., 1999). These outcomes may reflect glucocorticoid regulation of dopamine release (Thomas et al., 1994; Piazza et al., 1996), extrasynaptic reuptake (Grundemann et al., 1998), or changes in dopamine metabolism (Lindley et al., 1999).

Either excessive or insufficient dopamine neurotransmission can impair prefrontal cognitive functions. Depletion of dopamine in prefrontal cortex (Brozoski et al., 1979; Collins et al., 1998) and acute noise stress-induced increases in prefrontal dopamine release (Arnsten and Goldman-Rakic, 1998) each produce similar deficits in monkeys assessed on delayed spatial working-memory tests. An inverted U-shaped relationship is also evident in rodents. Depletion of dopamine in rat prefrontal cortex (Simon et al., 1980; Bubser and Schmidt, 1990) and supranormal stimulation of prefrontal dopamine D1 receptors (Zahrt et al., 1997) both disrupt cognitive performance on delayed spatial alternation tests. Intracellular recordings from rodent prefrontal cortical slices are consistent with the possibility that these cognitive deficits arise from dopamine modulation of signal transfer to the soma from the dendritic tree (Zahrt et al., 1997; Birnbaum et al., 1999).

Among humans with stress-related psychiatric disorders, those with psychotic depression present most consistently with evidence of endogenous hypercortisolism (Evans et al., 1983; Nelson and Davis, 1997) and are impaired on tests of prefrontal-dependent functions including attention and response inhibition (Jeste et al., 1996; Kim et al., 1999; Schatzberg et al., 2000). More recently a study of Cushing's syndrome indicates that prolonged exposure to elevated cortisol disrupts selective attention, response inhibition, and performance on prefrontal-dependent tasks (Forget et al., 2000). On the basis of these findings in humans and animals, we now are investigating prefrontal cognitive functions before and after the administration of a steroid antagonist in humans with psychotic depression.

A final aspect of this study that warrants comment concerns line-of-sight reaching and manual laterality. Squirrel monkeys that presented with a left- or right-hand bias were nearly equally common in the sample we examined. This finding is consistent with 26 other primate species that all fail to exhibit a population-level lateral bias for simple retrieval behavior (Fagot and Vauclair, 1991). Far less is known about manual laterality and cognitive processing in primates. Reach attempt errors directed straight toward the box when the opening was oriented toward either side were made less often by squirrel monkeys in this study that presented with a left-hand bias. Left-hand (right cerebral hemisphere) superiority for tactile-spatial cognitive processing has been demonstrated previously in primates (Brizzolara et al., 1982; Horster and Ettlinger, 1985; Parr et al., 1997). Right hemispheric dominance for response inhibition has also been identified by eventrelated functional magnetic resonance imaging in healthy humans tested on go/no-go tasks using either hand (Konishi et al., 1998; Garavan et al., 1999). Right hemispheric dominance for response inhibition and lateral differences in spatial cognitive processing may account for the left-hand superiority in squirrel monkeys assessed on the line-of-sight reaching response test. Neuroimaging research with monkeys and apes may shed light on these aspects of cerebral lateralization and their role in prefrontal-dependent functions.

\section{REFERENCES}

Arnsten AF, Goldman-Rakic PS (1998) Noise stress impairs prefrontal cortical cognitive function in monkeys: evidence for a hyperdopaminergic mechanism. Arch Gen Psychiatry 55:362-368.

Bartus RT, Dean RL, Fleming DL (1979) Aging in the rhesus monkey: effects on visual discrimination learning and reversal learning. J Gerontol 34:209-219.

Birnbaum S, Gobeske KT, Auerbach J, Taylor JR, Arnsten AF (1999) A role for norepinephrine in stress-induced cognitive deficits: alpha-1adrenoceptor mediation in the prefrontal cortex. Biol Psychiatry 46:1266-1274. 
Brady AG (2000) Research techniques for the squirrel monkey (Saimiri). ILAR J 41:10-18.

Brizzolara D, De Nobili GL, Ferretti G (1982) Tactile discrimination of direction of lines in relation to hemispheric specialization. Percept Mot Skills 54:655-660.

Brozoski TJ, Brown RM, Rosvold HE, Goldman PS (1979) Cognitive deficit caused by regional depletion of dopamine in prefrontal cortex of rhesus monkey. Science 205:929-932.

Bubser M, Schmidt WJ (1990) 6-Hydroxydopamine lesion of the rat prefrontal cortex increases locomotor activity, impairs acquisition of delayed alternation tasks, but does not affect uninterrupted tasks in the radial maze. Behav Brain Res 37:157-168.

Cohen J, Cohen P (1983) Applied multiple regression/correlation analysis for the behavioral sciences, 2nd Edition. Hillsdale, NJ: Erlbaum.

Collins P, Roberts AC, Dias R, Everitt BJ, Robbins TW (1998) Perseveration and strategy in a novel spatial self-ordered sequencing task for nonhuman primates: effects of excitotoxic lesions and dopamine depletions of the prefrontal cortex. J Cognit Neurosci 10:332-354.

de Kloet ER, Oitzl MS, Joels M (1999) Stress and cognition: are corticosteroids good or bad guys? Trends Neurosci 22:422-426.

de Leon MJ, McRae T, Tsai JR, George AE, Marcus DL, Freedman M, Wolf AP, McEwen B (1988) Abnormal cortisol response in Alzheimer's disease linked to hippocampal atrophy. Lancet 2:391-392.

Diamond A (1990) Developmental time course in human infants and infant monkeys, and the neural bases of, inhibitory control of reaching. Ann NY Acad Sci 608:637-676.

Diamond A, Zola-Morgan S, Squire LR (1989) Successful performance by monkeys with lesions of the hippocampal formation on $\mathrm{AB}$ and object retrieval, two tasks that mark developmental changes in human infants. Behav Neurosci 103:526-537.

Dias R, Robbins TW, Roberts AC (1996) Primate analogue of the Wisconsin Card Sorting Test: effects of excitotoxic lesions of the prefrontal cortex in the marmoset. Behav Neurosci 110:872-886.

Di Paolo T, Bedard P, Daigle M, Boucher R (1986) Long-term effects of MPTP on central and peripheral catecholamine and indoleamine concentrations in monkeys. Brain Res 379:286-293.

Elsworth JD, Deutch AY, Redmond Jr DE, Sladek Jr JR, Roth RH (1987) Effects of 1-methyl-4-phenyl-1,2,3,6-tetrahydropyridine (MPTP) on catecholamines and metabolites in primate brain and CSF. Brain Res 415:293-299.

Evans DL, Burnett GB, Nemeroff CB (1983) The dexamethasone suppression test in the clinical setting. Am J Psychiatry 140:586-589.

Fagot J, Vauclair J (1991) Manual laterality in nonhuman primates: a distinction between handedness and manual specialization. Psychol Bull 109:76-89.

Forget H, Lacroiz A, Somma M, Cohen H (2000) Cognitive decline in patients with Cushing's syndrome. J Int Neuropsychol Soc 6:20-29.

Garavan H, Ross TJ, Stein EA (1999) Right hemispheric dominance of inhibitory control: an event-related functional MRI study. Proc Natl Acad Sci USA 96:8301-8306.

Goldman-Rakic PS, Brown RM (1981) Regional changes of monoamines in cerebral cortex and subcortical structures of aging rhesus monkeys. Neuroscience 6:177-187.

Grundemann D, Schechinger B, Rappold GA, Schomig E (1998) Molecular identification of the corticosterone-sensitive extraneuronal catecholamine transporter. Nat Neurosci 1:349-351

Harfstrand A, Fuxe K, Cintra A, Agnati LF, Zini I, Wikstrom AC, Okret S, Yu ZY, Goldstein M, Steinbusch H, Verhofstad A, Gustafsson J (1986) Glucocorticoid receptor immunoreactivity in monoaminergic neurons of rat brain. Proc Natl Acad Sci USA 83:9779-9783.

Hennessy JW, Cohen ME, Rosen AJ (1973) Adrenocortical influences upon the extinction of an appetitive runway response. Physiol Behav 11:767-770.

Horster W, Ettlinger G (1985) An association between hand preference and tactile discrimination performance in the rhesus monkey. Neuropsychologia 23:411-413.

Jentsch JD, Redmond Jr DE, Elsworth JD, Taylor JR, Youngren KD, Roth RH (1997) Enduring cognitive deficits and cortical dopamine dysfunction in monkeys after long-term administration of phencyclidine. Science 277:953-955.

Jentsch JD, Taylor JR, Elsworth JD, Redmond Jr DE, Roth RH (1999) Altered frontal cortical dopaminergic transmission in monkeys after subchronic phencyclidine exposure: involvement in frontostriatal cognitive deficits. Neuroscience 90:823-832.

Jeste DV, Heaton SC, Paulsen JS, Ercoli L, Harris J, Heaton RK (1996) Clinical and neuropsychological comparison of psychotic depression with nonpsychotic depression and schizophrenia. Am J Psychiatry 153:490-496.

Kim DK, Kim BL, Sohn SE, Lim SW, Na DG, Paik CH, Krishnan KR, Carroll BJ (1999) Candidate neuroanatomic substrates of psychosis in old-aged depression. Prog Neuropsychopharmacol Biol Psychiatry 23:793-807

Kirschbaum C, Wolf OT, May M, Wippich W, Hellhammer DH (1996) Stress- and treatment-induced elevations of cortisol levels associated with impaired declarative memory in healthy adults. Life Sci 58:1475-1483.

Konishi S, Nakajima K, Uchida I, Sekihara K, Miyashita Y (1998) No-go dominant brain activity in human inferior prefrontal cortex revealed by functional magnetic resonance imaging. Eur J Neurosci 10:1209-1213.
Lindley SE, Bengoechea TG, Schatzberg AF, Wong DL (1999) Glucocorticoid effects on mesotelencephalic dopamine neurotransmission. Neuropsychopharmacology 21:399-407.

Lupien SJ, Gaudreau S, Tchiteya BM, Maheu F, Sharma S, Nair NP, Hauger RL, McEwen BS, Meaney MJ (1997) Stress-induced declarative memory impairment in healthy elderly subjects: relationship to cortisol reactivity. J Clin Endocrinol Metab 82:2070-2075.

Lupien SJ, de Leon M, de Santi S, Convit A, Tarshish C, Nair NP, Thakur M, McEwen BS, Hauger RL, Meaney MJ (1998) Cortisol levels during human aging predict hippocampal atrophy and memory deficits. Nat Neurosci 1:69-73.

Lupien SJ, Gillin CJ, Hauger RL (1999) Working memory is more sensitive than declarative memory to the acute effects of corticosteroids: a dose-response study in humans. Behav Neurosci 113:420-430.

Lyons DM, Ha CM, Levine S (1995) Social effects and circadian rhythms in squirrel monkey pituitary-adrenal activity. Horm Behav 29:177-190.

Lyons DM, Wang OJ, Lindley SE, Levine S, Kalin NH, Schatzberg AF (1999) Separation induced changes in squirrel monkey hypothalamicpituitary-adrenal physiology resemble aspects of hypercortisolism in humans. Psychoneuroendocrinology 24:131-142.

McEwen BS, Sapolsky RM (1995) Stress and cognitive function. Curr Opin Neurobiol 5:205-216.

Means LW, Holsten RD (1992) Individual aged rats are impaired on repeated reversal due to loss of different behavioral patterns. Physiol Behav 52:959-963.

Micco DJ, McEwen BS, Shein W (1979) Modulation of behavioral inhibition in appetitive extinction following manipulation of adrenal steroids in rats: implications for the involvement of the hippocampus. J Comp Physiol Psychol 93:323-329.

Milgram NW, Head E, Weiner E, Thomas E (1994) Cognitive functions and aging in the dog: acquisition of nonspatial visual tasks. Behav Neurosci 108:57-68.

Milliken GW, Stafford DK, Dodson DL, Pinger CD, Ward JP (1991) Analyses of feeding lateralization in the small-eared bush baby (Otolemur garnettii): a comparison with the ring-tailed lemur (Lemur catta). J Comp Psychol 105:274-285.

Nelson JC, Davis JM (1997) DST studies in psychotic depression: a metaanalysis. Am J Psychiatry 154:1497-1503.

Nelson MD, Saykin AJ, Flashman LA, Riordan HJ (1998) Hippocampal volume reduction in schizophrenia as assessed by magnetic resonance imaging: a meta-analytic study. Arch Gen Psychiatry 55:433-440.

Newcomer JW, Craft S, Askins K, Hershey T, Bardgett ME, Csernansky JG, Gagliardi AE, Vogler G (1998) Glucocorticoid interactions with memory function in schizophrenia. Psychoneuroendocrinology 23:65-72.

Newcomer JW, Selke G, Melson AK, Hershey T, Craft S, Richards K, Alderson AL (1999) Decreased memory performance in healthy humans induced by stress-level cortisol treatment. Arch Gen Psychiatry 56:527-533.

O'Brien JT, Ames D, Schweitzer I, Colman P, Desmond P, Tress B (1996) Clinical and magnetic resonance imaging correlates of hypothalamicpituitary-adrenal axis function in depression and Alzheimer's disease. Br J Psychiatry 168:679-687.

Parr LA, Hopkins WD, de Waal FB (1997) Haptic discrimination in capuchin monkeys (Cebus apella): evidence of manual specialization. Neuropsychologia 35:143-152.

Peters A (1993) The absence of significant neuronal loss from cerebral cortex with age. Neurobiol Aging 14:657-658.

Peters A, Rosene DL, Moss MB, Kemper TL, Abraham CR, Tigges J, Albert MS (1996) Neurobiological bases of age-related cognitive decline in the rhesus monkey. J Neuropathol Exp Neurol 55:861-874.

Peters A, Sethares C, Moss MB (1998) The effects of aging on layer 1 in area 46 of prefrontal cortex in the rhesus monkey. Cereb Cortex 8:671-684.

Peters A, Moss MB, Sethares C (2000) Effects of aging on myelinated nerve fibers in monkey primary visual cortex. J Comp Neurol 419:364-376.

Piazza PV, Rouge-Pont F, Deroche V, Maccari S, Simon H, Le Moal M (1996) Glucocorticoids have state-dependent stimulant effects on the mesencephalic dopaminergic transmission. Proc Natl Acad Sci USA 93:8716-8720.

Raz N, Gunning-Dixon FM, Head D, Dupuis JH, Acker JD (1998) Neuroanatomical correlates of cognitive aging: evidence from structural magnetic resonance imaging. Neuropsychology 12:95-114.

Roberts AC, De Salvia MA, Wilkinson LS, Collins P, Muir JL, Everitt BJ, Robbins TW (1994) 6-Hydroxydopamine lesions of the prefrontal cortex in monkeys enhance performance on an analog of the Wisconsin Card Sort Test: possible interactions with subcortical dopamine. J Neurosci 14:2531-2544.

Sanchez MM, Young LJ, Plotsky PM, Insel TR (2000) Distribution of corticosteroid receptors in the rhesus brain: relative absence of glucocorticoid receptors in the hippocampal formation. J Neurosci 20:4657-4668.

Schatzberg AF, Posener JA, DeBattista C, Kalehzan BM, Rothschild AJ, Shear PK (2000) Neuropsychological deficits in psychotic versus nonpsychotic major depression and no mental illness. Am J Psychiatry 157:10951100 .

Sheline YI, Sanghavi M, Mintun MA, Gado MH (1999) Depression duration but not age predicts hippocampal volume loss in medically healthy women with recurrent major depression. J Neurosci 19:5034-5043.

Simon H, Scatton B, Moal ML (1980) Dopaminergic A10 neurones are involved in cognitive functions. Nature 286:150-151. 
Slovin H, Abeles M, Vaadia E, Haalman I, Prut Y, Bergman H (1999) Frontal cognitive impairments and saccadic deficits in low-dose MPTPtreated monkeys. J Neurophysiol 81:858-874.

Starkman MN, Giordani B, Gebarski SS, Berent S, Schork MA, Schteingart DE (1999) Decrease in cortisol reverses human hippocampal atrophy following treatment of Cushing's disease. Biol Psychiatry 46:1595-1602.

Taylor JR, Elsworth JD, Roth RH, Collier TJ, Sladek Jr JR, Redmond Jr DE (1990a) Improvements in MPTP-induced object retrieval deficits and behavioral deficits after fetal nigral grafting in monkeys. Prog Brain Res 82:543-559.

Taylor JR, Elsworth JD, Roth RH, Sladek Jr JR, Redmond Jr DE (1990b) Cognitive and motor deficits in the acquisition of an object retrieval/ detour task in MPTP-treated monkeys. Brain 113:617-637.

Taylor JR, Roth RH, Sladek Jr JR, Redmond Jr DE (1990c) Cognitive and motor deficits in the performance of an object retrieval task with a barrier-detour in monkeys (Cercopithecus aethiops sabaeus) treated with
MPTP: long-term performance and effect of transparency of the barrier. Behav Neurosci 104:564-576.

Thomas DN, Post RM, Pert A (1994) Central and systemic corticosterone differentially affect dopamine and norepinephrine in the frontal cortex of the awake freely moving rat. Ann NY Acad Sci 746:467-469.

Wenk GL, Pierce DJ, Struble RG, Price DL, Cork LC (1989) Age-related changes in multiple neurotransmitter systems in the monkey brain. Neurobiol Aging 10:11-19.

Westergaard GC, Byrne G, Suomi SJ (1998) Early lateral bias in tufted capuchins (Cebus apella). Dev Psychobiol 32:45-50.

Young AH, Sahakian BJ, Robbins TW, Cowen PJ (1999) The effects of chronic administration of hydrocortisone on cognitive function in normal male volunteers. Psychopharmacology (Berl) 145:260-266.

Zahrt J, Taylor JR, Mathew RG, Arnsten AF (1997) Supranormal stimulation of D1 dopamine receptors in the rodent prefrontal cortex impairs spatial working memory performance. J Neurosci 17:8528-8535. 